\title{
Çocukluk Çağı Beyin Abseleri
}

\section{Brain Abscess In Children}

\author{
Feyza Ustabaş Kahraman ${ }^{1}$, Özden Türel ${ }^{1}$, Tolga Turan Dündar ${ }^{2}$, Mehmet Hakan Seyithanoğlu ${ }^{2}$
}

1 Bezmialem Vakif University, Pediatrics, Istanbul, Turkey

2 Bezmialem Vakif University, Brain Neurosurgery, Istanbul, Turkey
ÖZ

Amaç: Otitin komplikasyonu olarak beyin absesi sıklığı azalmışıtır. Sinüzitten kaynaklanan beyin absesi ise hem yetişkinlerde hem çocuklarda önemli bir yer teşkil etmektedir. Bu çalışmada otojenik ve sinojenik kaynaklı 6 beyin absesi vakas sunuyoruz.

Gereç ve yöntem: Ocak 2013 ile Mayıs 2017 tarihleri arasında intrakraniyal abse ile yatırılan çocukların verileri geriye dönük olarak değerlendirildi. Önceden belirleyici faktörler, klinik bulgular ve prognoz belirlendi.

Bulgular: İntrakraniyal abse bulunan 8 çocuk arasında 6'sı otogenik ve / veya sinogenik enfeksiyona sahipti. En sık görülen semptom baş ağrısıydı. İntrakraniyal abse 3 olguda epidural, 3 olguda parankimaldi. Etken patojenler olarak Streptokok intermedius, Streptococcus pyogenes, Provotella ile Propionibacterium acnes tespit edildi. Tüm çocuklara antibiyoterapi ve cerrahi drenaj uygulandı. Nörolojik sekel ve ölüm gerçekleşmedi.

Sonuç: Sinüzit ve otitis media; antibiyotik kullanımının artmasına rağmen, beyin abseleri için hala önemli birer predispozan faktördür.

Anahtar Kelimeler: Çocuk, Köpek ısırması
ABSTRACT

Background and aims: Brain abscess as a complication of ear infections has decreased in frequency. By contrast, brain abscess arising from a sinus infection remains an important consideration in both adults and children. Here we present 6 cases with brain abscess due to otogenic or sinogenic complications.

Methods: Data of children hospitalized with intracranial abscess between January 2013 and May 2017 were evaluated retrospectively. Predisposing factors, clinical manifestations and prognosis were identified

Results: Among 8 children with intracranial abscess 6 had otogenic and/or sinogenic infection. The most frequent symptom was headache. Intracranial abscess was epidural in 3 cases and parancimal in 3 cases. Causative pathogens were Streptococcus intermedius, Streptococcus pyogenes, and Propionibacterium acnes with Provotella loescheii. All children received antibiotherapy and surgical drainage. Neurological sequelae and death did not occur

Conclusion: Despite the increased use of antibiotics, sinüsitis and otitis media is an important predisposing factor for brain abcess.

Keywords: Children, Dog bites

Corresponding Author: Feyza USTABAŞ KAHRAMAN, Dr. Öğretim Üyesi

Address: ,Bezmialem Vakıf Üniversitesi Tıp Fakültesi, Çocuk Sağlığı ve

Hastalıkları Anabilim Dalı ,istanbul, Türkiye 


\section{Giriş}

Çocuklarda intrakraniyal abse nadir görülür ve çoğunlukla altta yatan predispozan durumlar söz konusudur (1). Beyin absesi, beyin dokusu içinde lokalize olmuş serbest veya enkapsüle pü odağıdır. Mikroorganizmalar beyin dokusuna üç değişik yolla ulaşır. En sık görülen patojenik mekanizma ortakulak, mastoid hücreler veya paranasal sinüslerden infeksiyonun direkt yayılımıdır. Daha ender görülen yollar ise mikroorganizmaların uzak bir odaktan hematojen yolla yayılımı ve penetran kafa tramvası ile direkt inokülasyonudur (2-4).

Gelişmekte olan ülkelerdeki intrakraniyal abse oluşumlarının en önemli sebebi, kronik süpüratif orta kulak iltihabıdır (5-7). Orta kulak iltihabı ve mastoidit vakalarının \%6 ile \%10 unda beyin absesi görülür $(8,9)$. Sinüzit vakalarının \%6-8 inde beyin absesi görülmektedir (8). İnfeksiyonun başlangıç döneminde klinik bulgular nonspesifiktir.

Nöbet, baş ağrısı, kusma gibi semptomlar ve özellikle altta yatan predispozan sebep varsa mutlaka düşünülmelidir. Tanı nörolojik görüntüleme yöntemleriyle konur. Manyetik rezonans (MR) görüntüleme, bilgisayarlı tomografi (BT) taramasından daha hassas olduğu için beyin apsesinde seçilen görüntüleme çalışmasıdır.

$\mathrm{Bu}$ çalışmada otojenik veya sinogenik komplikasyonlar nedeniyle beyin abseli 6 olgu sunulmuştur.

\section{Gereç ve Yöntem}

Çalışmamıza pediatri kliniğimizde Ocak 2013 ile Mayıs 2017 tarihleri arasında intrakraniyal abse ile yatırılan çocukların verileri geriye dönük olarak değerlendirildi. Olguların demografik özellikleri, etyoloji, klinik bulguları ve üreyen mikroorganizmalar dosya kayıtlarından incelendi.

\section{Bulgular}

Intrakraniyal abse tanısı konan 8 çocuğun 6 sında otojenik ve/veya sinojenik enfeksiyon vardı (1'i otit, 4'ü sinüzit, $1^{\prime} i$ otit+sinüzit). Olguların yaş ortalaması 9 (3-15 yaş) olup 4'ü kız (\%66) ve 2'i erkekti (\%34). Olgulara ait demografik özellikler tablo-1a ve tablo $1 b^{\prime}$ de görülmektedir.

Tablo 1a. Olgulara ait demografik ve klinik özellikler

\begin{tabular}{|c|c|c|c|c|c|c|c|}
\hline Olgular & cinsiyet & yaș & ates & kusma & $\frac{\underline{\text { bass }}}{\underline{\text { ağrıs! }}}$ & $\frac{\text { bilinç }}{\text { değișikliği }}$ & $\begin{array}{l}\frac{\text { fokal }}{\text { nörolojik }} \\
\underline{\text { bulgu }}\end{array}$ \\
\hline$\underline{1}$ & $\underline{K_{1 Z}}$ & $\underline{3}$ & yok & yok & yok & yok & var \\
\hline$\underline{2}$ & $\underline{K 1 z}$ & $\underline{14}$ & var & $\underline{\mathrm{var}}$ & $\underline{\text { var }}$ & yok & yok \\
\hline$\underline{3}$ & $\underline{\text { K1z }}$ & $\underline{11}$ & $\underline{\text { var }}$ & yok & var & yok & $\underline{\text { var }}$ \\
\hline$\underline{4}$ & $\underline{K 1 z}$ & $\underline{12}$ & yok & yok & $\underline{\text { var }}$ & yok & yok \\
\hline$\underline{5}$ & Erkek & $\underline{5}$ & yok & $\underline{\text { var }}$ & $\underline{\text { var }}$ & var & yok \\
\hline$\underline{6}$ & Erkek & $\underline{15}$ & $\underline{\text { var }}$ & $\underline{\text { var }}$ & $\underline{\text { var }}$ & yok & yok \\
\hline
\end{tabular}

Tablo 1b. Olgulara ait demografik ve klinik özellikler

\begin{tabular}{|c|c|c|c|c|c|c|c|}
\hline olgular & otit & sinüzit & $\frac{\text { abse }}{\text { lokalizasyonu }}$ & $\frac{\text { abse kültüründe }}{\text { üreme }}$ & tedavi & $\frac{\text { yatış }}{\text { süresi }}$ & $\frac{\text { nörolojik }}{\text { sekel }}$ \\
\hline$\underline{1}$ & var & yok & $\begin{array}{l}\text { parietoocipital } \\
\text { parankim }\end{array}$ & $\frac{\text { streptococcus }}{\text { intermedius }}$ & $\frac{\text { medikalt }}{\text { kraniyotomi }}$ & 23 & yok \\
\hline$\underline{2}$ & var & $\underline{\text { var }}$ & $\frac{\text { sol frontal }}{\text { parankim }}$ & üreme yok & $\frac{\text { medikalt }}{\text { kraniyotomi }}$ & $\underline{38}$ & yok \\
\hline$\underline{3}$ & yok & $\underline{\text { var }}$ & $\begin{array}{l}\text { sol temporal } \\
\text { epidural }\end{array}$ & üreme yok & $\begin{array}{l}\text { medikalt } \\
\text { kraniyotomi }\end{array}$ & $\underline{20}$ & yok \\
\hline$\underline{4}$ & yok & $\underline{\text { var }}$ & $\frac{\text { sol frontal }}{\text { epidural }}$ & $\frac{\text { streptococcus }}{\text { pyogenes }}$ & $\frac{\text { medikal+ }}{\text { kraniyotomi }}$ & $\underline{32}$ & yok \\
\hline$\underline{5}$ & yok & $\underline{\text { var }}$ & $\frac{\text { sağ frontal }}{\text { parankimal }}$ & $\frac{\text { streptococcus }}{\text { pyogenes }}$ & $\frac{\text { medikalt }}{\text { kraniyotomi }}$ & $\underline{29}$ & yok \\
\hline$\underline{6}$ & yok & var & $\frac{\text { sağ frontal }}{\text { epidural }}$ & $\begin{array}{l}\text { propionibacterium } \\
\text { acnes prevotella } \\
\text { loescheii }\end{array}$ & $\frac{\text { medikalt }}{\text { kraniyotomi }}$ & 30 & yok \\
\hline
\end{tabular}

En sık görülen semptom baş ağrısı idi (\%83). Diğer semptomlar; ateş (\%60), kusma (\%60), yüzde şişlik (\%60), göz ağrısı (\%60), yüz ağrısı (\%60), letarji (\%16), kulak ağrısı (\%16), kişilik değişikliği (\%16), inkontinans (\%16), hemparezi (\%33) idi. Olgulara beyin görüntülemesi için bilgisayarlı tomografi ve /veya manyetik rezonans görüntüleme yapıldı. Intrakraniyal abse 3 (\%50) olguda epidural, 3 (\%50) olguda parankimal olarak izlendi. 
Abse sıvısından yapılan kültürlerde Streptococcus intermedius, Streptococcus pyogenes, Provotella loescheii'li ve Propionibacterium acne üredi.

Olguların tümüne hem medikal (antibiyoterapi) hem de cerrahi tedavi uygulandı. Cerrahi işlemlerin kraniyotomi şeklinde olduğu tespit edildi. Olguların hastanede yatış süresi ortalama 30 gündü. Olguların hiçbirisinde nörolojik sekel ve ölüm gerçekleşmedi.

\section{Tartışma}

Beyin absesi, beyin parenkiminde yada subdural ve epidural mesafede lokalize olmuş serbest veya enkapsüle pü odağıdır. Enfeksiyon hematojen yolla uzak organlardan, direkt invazyonla komşu nonnöronal dokulardan veya penetre yara ve cerrahilerde patojenin ekimi sonucu gerçekleşmektedir (10). Klasik bulgu ve belirtilerinin olmayışı erken tanı almasını ve tedavi edilmesini engeller. Genel olarak, üçüncü dünya ülkelerinde beyin abselerinin, intrakraniyal kitle lezyonların \%8'ini oluşturduğu rapor edilmekte olup, bu abselerin $\% 25^{\prime} i$, en fazla 4 ile 7 yaş aralığında olmak üzere çocukluk yaş grubunda görülmektedir $(11,12)$. İlk iki dekadda görülen beyin abse olguları, erkek hastalrda sık görülmektedir. Erkek kadın oranı 1.5-3.1 arasında değişmektedir (13).

Beyin absesi baş ve boyun enfeksiyonlarının en ciddi komplikasyonudur. Her zaman predispozan bir durum mevcuttur. Gelişmekte olan ülkelerde intrakraniyal abse oluşumlarının en önemli sebebi, kronik süpüratif orta kulak iltihabıdır. Orta kulak iltihabı ve mastoidit vakalrının \%6 ile \% 10'unda beyin absesi görülür(8,9). Sinüzit vakalarının \%6-8'inde beyin absesi görülmektedir (8). Akut rinosinüzitin intrakraniyal komplikasyon insidansının\% 3-17 olduğu bildirilmiştir. Lerner ve ark.nın en büyük pediatrik serisi sinüzit ile başvuran çocuklarda\% 3 intrakraniyal komplikasyon oranını bildirmiştir (14). Intrakraniyal komplikasyonları olan 39 hastadan menenjit (\% 53.8), epidural apse (\% 15.4), subdural apse (\% 12.8), intraserebral apse (\% 10.3) ve Pott kabarıklığı tümörü (\% 2.6) komplikasyon olarak bildirilmiştir. Kuzey Amerika'da ; Nationwide Acil Servis 2008 veritabanına göre 101.600 çocuğu kapsayan çalışmada acil servisde akut bakteriyel sinüzit tanısı konan çocukların \%0.7'sinde komplikasyon belgelenmiştir. Komplikasyonları olan çocukların $\% 15^{\prime}$ inde periorbital selülit, $\% 76$ 'sında orbita komplikasyonları ve $\% 9^{\prime}$ unda intrakraniyal komplikasyon gelişmiştir. Komplikasyon gelişen 104 olgunun kohort çalışmasında 2 beyin absesi, 7 epidural ve 6 subdural ampiyem tespit edildi (15). Olgularımızda da otitis media, sinüzit gibi hazırlayıcı faktörler mevcuttur.

Beyin absesi olan çocuklarda görülen semptomlar ateş, baş ağrısı, nöbet ve kusma olarak tanımlanmaktadır. Öte yandan, baş ağrısı, ateş ve fokal nörolojik belirtilerin klasik triadı pediatri vakalarının yalnızca \%9 ile $\% 28$ 'inde gözlemlenmiştir. Çocukların \%30 ile $\% 70$ 'inde ateş, bu enfeksiyon sürecinin erken bir belirtisi olarak gözlemlenmiştir. Ateşin olmaması, pediatrik beyin abselerinde yalnızca \% 50'sinde görülmesi sebebiyle çocukta beyin absesi olmadığı anlamına gelmemelidir. Daha büyük abselerde kitle etkisi ve vazojenik ödem sonucu artan intrakranyal basınç, herniasyon olasılı̆̆ı ve /veya komşu parankim hasarına neden olan etkiden kaynaklanan nörolojik sorunlara sebep olur. Hemiparezi çocuklarda daha sık görülmektedir $(12,16,17)$. Diğer çalışmalarla uyumlu olarak, derlememizde en sık karşılaşılan belirtilerin baş ağrısı ve kusma ve ateş olduğu görüldü.

Pediatrik beyin abselerinde saptanan bakteriyel mikroorganizmaların \%60-70'i aerobik ve anaerobik streptokok, \%20-40 gram negatif anaerobik basiller, $\% 20-30$ 
enterobakterler, \%10-15 staf. Aureus olarak bildirilmiştir. Şantlı olgularda metisiline dirençli staf. Aureus sıklığı artmıştır. Bağışıklığı baskılanmış çocuklarda fungal patojenlerin sıklığı artmıştır $(3,9,12)$ Literatürde mikrobiyolojik etmenin tespit edilemediği steril abse oranı \%10-56 arasında bildirilmiştir $(1,18,19)$. Olgularımızın \% 33' ünde kültürlerinde üreme olmadığı tespit edildi. Kültürde üreme oranımızın azlığı önceki antibiyotik kullanımı, anaerop mikroorganizmalrı üretmedeki zorluk ve uygunsuz örnekleme teknikleri ile ilişkili olabilir.

Tanı nörolojik görüntüleme yöntemleriyle konulur. Eğer manyetik rezonans görüntüleme (MRG) yapılamıyorsa bilgisayarlı beyin tomografisi (BBT) tercih edilir. En sık abse lokalizasyonu parietal ve /veya frontal lob olarak bulunmuştur. Canpolat ve ark. çalışmasında abselerin \%80'i supratentorial, $\% 5$ 'i infratentorial, $\% 15$ ' $i$ hem supratentorial hem de infratentorial bulunmuştur (19). Olgularımızın \%50 si epidural, \%50 parankimal yerleşimlidir, en sık lokalizasyon frontal bölgede bulunmuştur.

Beyin abselerinde tanı konulur konulmaz antibiyoterapi başlanmalıdır. Başlangıç tedavisi hem aerobik, hem anaerobik mikroorganizmalara etki edecek şekilde seçilmelidir. Etken patojen tespit edildikten sonra ajana yönelik etkili ve beyin dokusuna penetrasyon gücü yüksek antibiyotikler tercih edilmelidir. Ampirik antibiyoterapi sıklıkla nafsillin, vankomisin veya sefotaksim, seftriakson ve metranidazolu içerir. Tedavi süresi 6-8 hafta intravenöz antibiyotik şeklindendir $(12,20,21,22)$.

Cerrahi tedavi endikasyonları; çapı $2.5 \mathrm{~cm}$ den büyük abseler, ciddi kafa içi basınç artışı, intraventriküler rüptür riski, medikal tedaviye yanıt alınamaması, mikotik enfeksiyonlar, yabancı cisim veya kemik fragmanların olduğu kafa tramvalarına sekonder gelişen abseler(8,12,23). Olgularımızda öncelikli uygulamanın Burr-hole drenaj olduğu, ancak bu şekilde ulaşılamayan, daha küçük ve zor lokalizasyonlu abselerde ise kraniyotomi şeklinde olduğu belirlenmiştir.

Mortalite hızı 1980' lere kadar \%40-60 iken, radyolojik görüntüleme ve mikrobiyolojik tekniklerdeki ve tedavi alanındaki gelişmelerle bu oran \%3.7-12'lere düşmüştür(1,12,18,19). Hiçbir olgumuzda mortalite gerçekleşmediği belirlendi.

Sonuç olarak intrakranyal abseler çocukluk çağında nadir olmalarına rağmen mortalite ve morbidite hızları sebebiyle önemlidir. Ani başlayan baş ağrısı, ateş ve nörolojik semptomlarla başvuran olgularda bu tanı akla gelmeli, gerekli tanı ve tedavi basamakları uygulanmalıdır.

\section{Kaynaklar}

1. Shachor-Meyouhas Y, Bar-Joseph G, Guilburd JN, Lorber A, Hadash A, Kassis I. Brain abscess in children epidemiology, predisposing factors and management in the modern medicine era. Acta Paediatr 2010; 99(8):1163-1167.

2. Ravdin JI. Brain abcesses. In: Mandell GL, Bennet JE, Dolin R, eds. Principles and Practice of Infectious Diseases. New York: Churchill Livigstone, 1995:1016-28.

3. Ersabin $Y$, Mutluer $S$, Güzelbağ E. Brain abcess in infants and children. Childs Nerv Syst 1994; 10: 185-9.

4. Weil ML, Tuomanen E, Israele V, Rust R, Menkes JH. Infections of the nervous system. In: Menkes JH, Sarnat HB, eds. Child Neurology. Philadelphia: Lippincott Williams\&Wilkins, 2000:500-6.

5. Dubey SP, Larawin V: Complications of chronic suppurative otitis media and their management. Laryngoscope 117:264-267, 2007

6. Joshi SM, Devkota UP: The management of brain abscess in a developing country: are the results any different? $\mathrm{Br}$ J Neurosurg 12:325-328, 1998

7. Kurien $M$, Job $A$, Mathew J, Chandy $M$ : Otogenic intracranial abscess: concurrent craniotomy and mastoidectomy - changing trends in a developing country. Arch Otolaryngol Head Neck Surg 124:1353-1356, 1998

8. Ciurea AV, Stoica F, Vasilescu G, Nuteanu L: Neurosurgical management of brain abscesses in children. Child's Nerv Syst 15:309-317, 1999

9. Xiao F, Tseng MY, Teng LJ, Tseng HM, Tsai JC: Brain abscess: clinical experience and analysis of prognostic factors. Surg Neurol 63:442-450, 2005

10. Sheehan JP, Jane JA, Ray DK, Goodkin HP. Brain abscess in children. Neurosurg Focus 2008; 24(6):E6.

11. Frazier JL, Ahn ES, Jallo GI: Management of brain abscesses in children. Neurosurg Focus 24: E8, 2008

12. . Gaskill SJ, Marlin AE: Brain abscesses and encephalitis, in Albright AL, Pollack IF, Adelson PD (eds): Principles and Practice of Pediatric Neurosurgery, ikinci baskı, New York: Thieme, 2008: 1162-1181 
13. Greenberg MS: Cerebral abscess, in Greenberg MS (ed): Handbook of Neurosurgery, yedinci baskı, New York: Thieme, 2010: 350-353

14. Lerner DN1, Choi SS, Zalzal GH, Johnson DL. Intracranial complications of sinusitis in childhood Ann Otol Rhinol Laryngol. 1995 Apr;104(4 Pt 1):288-93.

15. Garin A, Thierry B, Leboulanger N, Blauwblomme T, Grevent D, Blanot S, Garabedian N, Couloigner V. Pediatric sinogenic epidural and subdural empyema: The role of endoscopic sinus surgery. Int J Pediatr Otorhinolaryngol. 2015 Oct;79(10):1752-60. doi: 10.1016/j.ijporl.2015.08.007. Epub 2015 Aug 13

16. Tekkök IH, Erbengi A. Management of brainabscess in children: review of 130 cases over a period of 21 years.Childs Nerv Syst. 1992;8:411-6.

17. Wong TT, Lee LS, Wang HS, Shen EY, Jaw WC, Chiang $\mathrm{CH}$ et al. Brain abscesses in children--a cooperativestudy of 83 cases Childs Nerv Syst. 1989;5:19-24

18. Demirören K, Gülşen I, Ece I, Garipardıç M, Sevgin B, Bulut MD et al. Çocuklarda intrakraniyal apse. Van Tıp Dergisi: 2015:22:67-72. 5.

19. Canpolat M, Ceylan O, Per H, Koc G, Tumturk A, Kumandas $S$ et al.Brain abscesses in children: results of 24 children from a reference center in Central Anatolia, Turkey. J Child Neurol. 2015;30:458-67.

20. Yogev R, Bar-Meir M. Management of brain abscesses in children. Pediatr Infect Dis J. 2004;23:157-9

21. Hakan T, Ceran N, Erdem I, Berkman MZ, Göktaş P. Bacterial brain abscesses: an evaluation of 96 cases. J Infect. 2006;52:359-66.

22. Felsenstein S, Williams B, Shingadia D, Coxon L, Riordan A, Demetriades AK et al. Clinical and emicrobiologic features guiding treatment recommendations for brain abscesses in children. Pediatr Infect Dis J. 2013;32:129-35

23. Rosenblum ML, Hoff JT, Norman D, Edwards MS, Berg BO. Nonoperative treatment of brain abscesses in selected highrisk patients. J Neurosurg. 1980;52:217-25.6. 